\title{
Examining the Impact of Job Satisfaction and Employee Engagement as Mediators between Job Crafting and Turnover Intention in Saudi Companies
}

\author{
Abdulmohsen A. Naasani ${ }^{1} \quad$ Sheikha M. Alotaibi $^{2} \quad$ Raghad S. Alothman ${ }^{2}$ \\ 1. Department of Management, College of Business Administration, King Saud University, P.O. Box 71115, \\ Riyadh 11587, Saudi Arabia \\ 2.Department of Human Resources Management, College of Business Administration, Prince Sattam bin \\ Abdulaziz University, P.O. Box 165, Akharj 11942, Saudi Arabia
}

\begin{abstract}
This study aims to investigate the impact of Job Satisfaction and Employee Engagement as Mediators between Job Crafting and Turnover Intention. By Examining 190 private sector employees in Saudi Arabia and using linear regressions Analysis and validated questionnaire, the results of the study show that (1) There is a positive relationship between job crafting and job satisfaction, (2) Job crafting is a positively related to employee engagement. Also (3) There is a positive relationship between job satisfaction and employee engagement. Whereas (4) Job satisfaction and turnover intention is negatively related to each other. Finally, it has been found that (5) There is a negative relationship between employee engagement and turnover intention. These findings suggest that the turnover intention of employees could be reduced through empowering employees by generating job-crafting behaviors. Thus, will lead eventually to job satisfaction and employee engagement.
\end{abstract}

Keywords: job satisfaction, employee engagement, job crafting, turnover intention

DOI: $10.7176 / \mathrm{EJBM} / 13-7-09$

Publication date: April $30^{\text {th }} 2021$

\section{Introduction}

The rapid technological advancements and varying macro-environmental factors and their impact on an organization's microenvironment are not only increasing the heat of hyper-competitive corporate environment but stimulating a notable shift in the employment relationships as the employee turnover is increasing and employees' loyalty is declining (Klehe, Zikic, Vianen, \& Pater, 2011). An upward shift in employee turnover imposes recruitment and training cost on the employer, disrupt the routine working tasks due to vacant positions, and decline to the morale of existing employees, which, negatively impact the organization's performance and employer branding (Slatten, Svensson, \& Sværi, 2011). Employees' intent to leave the organizations can better predict whether the company is going to experience loyalty or employee defection. The recent developments have surged the need to change the job designs and the individual activities to meet the mounting challenges, which are otherwise difficult to combat with the conventional approaches to organize work into activities (Dubbelt, Demerouti, \& Rispens, 2019). The research has suggested that, in this situation, job crafting, a bottomup job design, contributes to the realization of positive results because it increases the employees' work engagement and job performance (Oprea, Barzin, Vîrga, Iliescu, \& Rusu, 2019). "Job crafting is a series of selfimposed employee behaviors that alter their job tasks and the boundaries of the relationship in order to align their interests, motivations, and passion with the job" (Wrzesniewski \& Dutton, 2001, p. 195). Three volunteer behaviors are engaged in job crafting, which includes increasing the job resources, augmenting the complex job requirements, reducing the inhibiting job demands (Tims, Bakker, \& Derks, 2012). The impact of job crafting on the turnover intentions has been widely researched (Chiu, 2017; Esteves \& Lopes, 2017; Karatepe \& Eslamlou, 2017; Dominguez, et al., 2018; Vermooten, Boonzaier, \& Kidd, 2019; Opre, Paduraru, \& Iliescu, 2020; Zhang \& $\mathrm{Li}, 2020)$. In the promotion-focused job crafting, employees design their jobs considering challenges and resources, which raise the meaningfulness of the job tasks (Clausen \& Borg, 2011), which, in turn, negatively impact the turnover intent (Chang, Wang, \& Huang, 2013; Janik, 2015; Arnoux-Nicolas, Sovet, Lhotellier, Fabio, \& Bernaud, 2016; Caillier, 2020). Considering the Job Demand- Resouce theory as a conceptual framework, some studies have suggested that job demands and job resources reduce the employees' intent to leave the job (Podsakoff, LePine, \& LePine, 2007; Jourdain \& Chenevert, 2010; Jang, et al., 2017).

According to Schaufeli, Bakker, and Salanova (2006), work engagement is a positive, fulfilling, workrelated state of mind that is characterized by vigor, dedication, and absorption" (p. 702). Job crafting increases work engagement because when the employees are empowered to redesign their jobs and perform the challenging tasks with adequate resources, they tend to be more committed to their work (Tims \& Bakker, 2010; Bakker, Tims, \& Derks, 2012; Chen, Yen, \& Tsai, 2014; Siddiqi, 2015; Beer, Tims, \& Bakker, 2016; Aldrin \& Merdiaty, 2019)), which, in turn, reduce the turnover intent (Sjoberg \& Sverke, 2000; Huang, Lawler, \& Lei, 2007; Azeez, Jayeoba, \& Adeoye, 2016). 
Job satisfaction is an employee's positive behavior towards his job. Job satisfaction can be developed and enhanced through job crafting (Heuvel, Demerouti, \& Peeters, 2015) as it enables employees to bring harmony between job demands and resources (Tim, Bakker, \& Derks, 2013) and enjoy their job. The research has suggested a positive connection between job crafting and job satisfaction (Lambert, Hogan, \& Barton, 2001; Tett $\&$ Meyer, 1993). It has also been suggested that job satisfaction stimulated by job crafting reduces the turnover intentions (Freund, 2005; Zhang \& Li, 2020) because once an employee designs the job fitting to his skills and preferences, he is less likely to leave it.

The literature has suggested that job satisfaction and work engagement, strengthened by job crafting, reduce turnover intentions. However, none of the past studies have explored these relationships in the Saudi context. To address this shortcoming, this study intends to investigate the job satisfaction and employee engagement as mediators between job crafting and turnover intention.

\section{Theoretical Background and Hypothesis Development}

\subsection{The relationship between job crafting and job satisfaction}

Ghitulescu (2006) explored that employees who had experience in job crafting had more commitment to their works, hence having higher job satisfaction levels. According to van den Heuvel, Demerouti, \& Peeters (2015), job satisfaction is a positive reaction to the job and showed that the employee has a favorable job behavior. It has been indicated that job crafting can enhance job satisfaction. Work conditions can impact job satisfaction; hence job satisfaction can be increased by an effective work environment. (Parvin \& Kabir, 2011).

Ren, T., Cao, L., \& Chin, T. (2020) have been examined the relationships of the expansive job crafting behaviors (JCB) with occupational satisfaction and innovation workplace behavior (IWB) with a sample of manufacturing organizations in China that is facing the threat of COVID-19. The result indicated that expansive JCB is positively associated with occupational satisfaction.

Cheng, J.-C., \& O-Yang, Y. (2018) studied job crafting and job satisfaction in the hospitality industry, finding that job crafting is positively related to job satisfaction since job crafting enhances job resources. Furthermore, Hotel employees more probably feeling satisfaction if they have adequate resources in their works.

Slemp and Vella-Brodrick (2014) have revealed that employees utilize job crafting to satisfy job needs and allow them to form their job, which leads to increased job satisfaction. Therefore, the following hypothesis is proposed:

H1: There is a positive relationship between job crafting and job satisfaction.

\subsection{The relationship between job crafting and employee engagement}

In an effort to make a unique contribution to the relevant literature, Tims, Bakker, Derks ,

and Rhenen (2013) examined the job crafting at the team and individual level concerning work engagement and employee performance. Based on the relevant reviewed literature, it was hypothesized that the team (individual) job crafting stimulates performance through team (individual) work engagement. Utilizing the quantitative research design, the data was collected from individuals and teams in the healthcare sector. The findings have revealed that job crafting can't trigger expected performance unless the team (individuals) are engaged in the work. It shows that work engagement is not only directly linked with job crafting but also mediates the job crafting-job performance relationship.

Siddiqi (2015) explored the role of service employees' work engagement and job crafting in realizing desired customer outcomes. It was found that the job crafting skills and behaviors of employees positively stimulate employees' work engagement and customer satisfaction and loyalty for the company. The more the employees are allowed to modify the boundaries of their jobs, the more they tend to be engaged with their workplaces, and the more they are willing to move beyond the customers' expectations.

Beer, Tims, and Bakker (2016) examined the impact of job crafting on the work engagement and job satisfaction of employees in the mining and manufacturing sector. At different points of time, the surveys were conducted to investigate the positive relationship between job crafting and work engagement and between job crafting and job satisfaction. The study suggested that the employers would experience employees' increasing work engagement if they provide the employees with job crafting opportunities.

The literature has shown a positive relationship between job crafting and work engagement. Therefore, the following hypothesis is proposed:

H2: There is a positive relationship between job crafting and employee engagement.

\subsection{Relationship between job satisfaction and employee engagement}

In their study, Park and Johnson (2019) found a significantly positive relationship between job satisfaction and work engagement. Both intrinsic and extrinsic job satisfaction stimulate the level of employees' engagement at work. The more an employee is intrinsically satisfied, the more he tends to be engaged in the workplace. Health science teachers need to have an expressive level of achievement, proficiency, and empowerment to be 
intrinsically satisfied. It has also been found that job satisfaction and work engagement, cumulatively, subside employees' turnover intention because satisfied employees tend to be more engaged in the work which prevents them from leaving the companies.

Zhang, Bian, Bai, Kong, Liu, Chen, and Li (2020) found in their study that job satisfaction and work engagement were significantly correlated with each other. Average or low satisfaction was found among rural physicians as they were assigned to the tasks more than they could handle; no chances for promotions; insufficient compensation; low social security as compared to their urban counterparts; and lack of training or skill development opportunities. In the existence of these factors, rural physicians tend to be dissatisfied with their jobs, and thus, they were not engaged in rural clinics. It has also been found the work engagement modified the relationship of job satisfaction with other factors such as turnover intentions and resilience.

Kasparkova, Vaculík, Prochazka, and Schaufeli (2018) found in their study that, being positively correlated with each other, job satisfaction and work engagement significantly impact employees' performance. Among the Czech workers, it was found that the higher the employees are satisfied, the more they tend to be engaged in the workplace, and the better their performance tends to be. Job satisfaction suppresses the impact of negative emotions at work and induces employees to voluntarily contribute to workplace performance.Therefore, the following hypothesis is proposed:

H3: There is a positive relationship between job satisfaction and employee engagement.

\subsection{The relationship between job satisfaction and turnover intention}

Considering the importance of employees' job satisfaction/dissatisfaction in impacting the employees' intention to leave the company, Randhawa (2007) conducted a study to investigate the relationship between job satisfaction and turnover intentions. The correlation analysis has revealed that job satisfaction and turnover intentions are negatively related to each other. The more the employees are satisfied, the lower they tend to have turnover intention.

Identifying the weaknesses of the past studies exploring the relationship between job satisfaction and turnover intents, Amah (2009) examined the subject relationship while assessing the moderating impact of job role centrality and life satisfaction on it. The study results indicated that job satisfaction and turnover intent are negatively related to each other. However, this relationship is significantly moderated by an employee's life satisfaction and centrality of the role. An employee who is not satisfied with life is more likely to have turnover intent even if he is satisfied with his job. It has also been found that the higher the role centrality, the higher the job satisfaction, and the lower the turnover intents.

Considering the association of job satisfaction with organizational policies and tactics, supervision effectiveness, compensation, the unambiguity of an assigned role, and career development programs, Alam and Asim (2019) conducted a study to explore the relationship between job satisfaction and turnover intention as well as the impact of job satisfaction on the intent to leave among healthcare nurses. The multiple regression analysis has revealed that all five dimensions of job satisfaction were negatively related to employees' turnover intention. Alam and Asim (2019) have suggested that employers must have employee-friendly policies, provide career development opportunities to them, offer competitive compensation, and provide clear job descriptions to keep the employees satisfied and avoid experiencing employees' voluntary turnover.

Liu, Zhu, Wu, and Mao (2019) conducted a study to examine job satisfaction, work stress, and turnover intentions of rural health workers and explore the critical factors associated with the health workers' turnover intent. The results indicated that the rural health workers were not much satisfied with their jobs. Their compensation level, institute's market position, and job satisfaction determine whether they will stay with the same institute or have the turnover intention. It has been suggested that the higher the job satisfaction, income, and medical institute's market position, the lower the turnover intentions will be.

Considering the positive impact of job satisfaction on employees' performance and loyalty and the negative impact of the turnover intention on the organization's performance, Rahman (2020) examined a relationship between job satisfaction and turnover intention among the employees in Bangladesh.The in-depth analysis and multiple regression analysis have revealed that job satisfaction and turnover intention are negatively related to each other. It has also been found that job security, compensation, promotion are negatively related to turnover intention. It has been suggested that employers should offer competitive compensation to employees and provide assurance for their job security, and merit-based promotions for keeping employees satisfied with their jobs, which would, in turn, reduce their turnover intent.

The review of past studies has revealed that job satisfaction negatively impacts turnover intent. Therefore, the following hypothesis is proposed:

H4: There is a negative relationship between job satisfaction and turnover intention.

2.5 The relationship between employee engagement and turnover intention

Schaufeli et al. (2002) considered employee engagement to help employees to commit to their job, and they are 
struggling to separate themselves after works have been done; thus, they are seeking to develop themselves in their present company. In the framework of this, the researchers supported that employees who engaged are less in looking for other jobs in different organizations. According to Iddagoda, Opatha, \& Gunawardana (2016), engaged employees are seen as being loyal, innovative, creative and customer-focused, and are ready to keeping employment with the organization. Fundamentally, engaged employees work harder to accomplish company goals and objectives.

Kim (2017) conducted a study among private sector companies, examined the potential relationships between work engagement, turnover intention, and other variables. In consideration of this, the study has shown the negative impact of employee engagement on turnover intention. Organizational employees who are fully engaged struggle to leave the organization since they invested in their work related to high work performance. As per the research among public and private organizations conducted by Barbosa de Oliveira and da Costa Rocha (2017), concluded the negative association between employee engagement and turnover intention.

Park, K. A., \& Johnson, K. R. (2019) conducted a study to investigate the relationships between job satisfaction, work engagement, and turnover intention of health science teachers. The result indicated that work engagement-vigor, dedication, and absorption negatively associated with turnover intention, proposing that as work engagement increases, turnover intention decreases. Therefore, the following hypothesis is proposed:

H5: There is a negative relationship between employee engagement and turnover intention.

\subsection{Gaps Identification}

The most of the researches on this topic have been conducted in Individualistic countries, where the importance is placed on individual rights and freedom, such as the United States. (Oyserman \& Lee, 2008). Researches show that individualistic countries are different from collectivistic ones, where the importance is placed on groups respect and obedience, such as Arab countries (Chiu \& Hong, 2006). Thus, we need to conduct more research on the impact of job crafting and employee engagement and job satisfaction on turnover intention in countries that differ from the dominant countries in the mainstream literature. With this in mind, Saudi Arabia is chosen since it is one of the countries classified as a collectivistic society (Al-Ruwatiea, 2004). Furthermore, this research is different from other researches since it will shed light on job satisfaction and employee engagement as a moderator in the relation between job crafting and turnover intention in Saudi Arabia.

\subsection{Research Model}

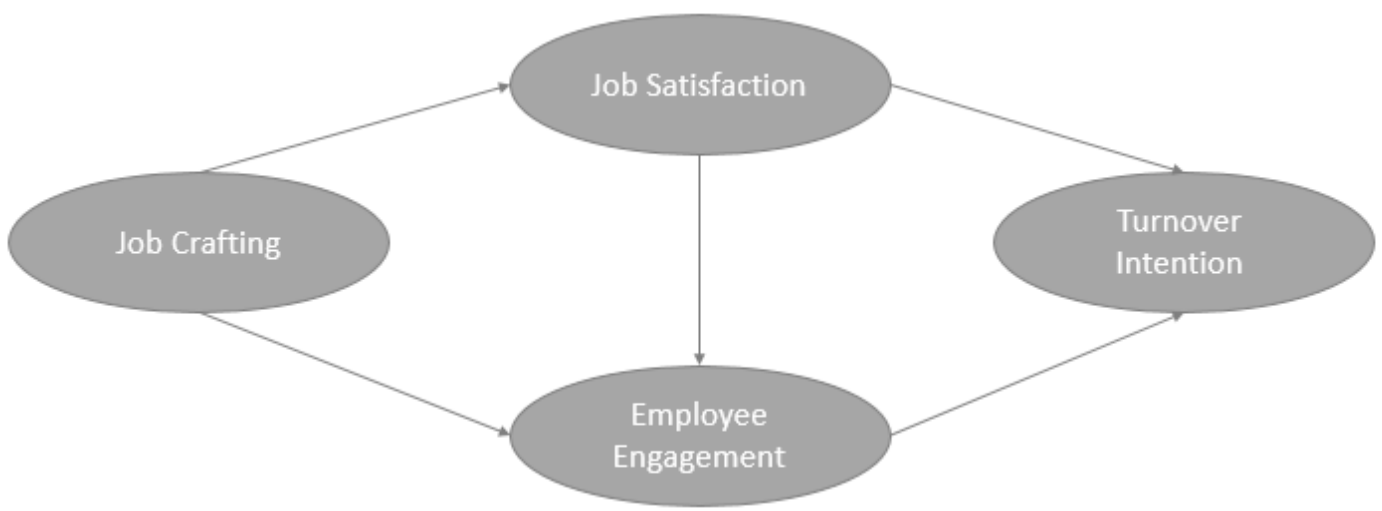

Figure 1. A theoretical model of hypothesis for the study

\section{Methodology}

3.1 Sample and data collection

The study population was salaried employees. The sample was drawn from the private sector employees in Saudi Arabia. The data was collected through a self-administered questionnaire evaluating the study variables, i.e. job crafting, job satisfaction, employee engagement, and turnover intentions. Using the random sampling technique, the questionnaire was sent to 250 employees, the study sample. However, the response rate was $76 \%$ as only 190 questionnaires were fully responded to.

\subsection{Measures}

Reliable and valid scales of past studies were adopted to collect the needed data on each of the variables. To collect the measurable responses on job crafting, job satisfaction, employee engagement, and turnover intention, a 5-point Likert scale [1 (strongly disagree), 2 (disagree), 3 (neutral), 4 (agree), 5 (strongly disagree)] was used. To measure job crafting, 14 items were selected from Job Crafting Scale (Bindl, Unsworth, Gibson, \& Stride, 
2019). To measure the work engagement, 9 items from Work and Well-Being Survey (UWES) items were used. Three items were selected from job Satisfaction Survey scale (Yang, Jixia, Mossholder, Kevin \& Peng, 2009) for measuring the job satisfaction of the respondents. Moreover, for measuring the employees' turnover intentions, 5 items were chosen from Turnover Intention Scale (Mowday, Koberg, \& McArthur, 1984). The data were analyzed using SPSS (Statistical for the Social Sciences) and AMOS (Analysis of Moment Structures).

\section{Analysis}

4.1 Descriptive Statistics and Correlations

Table 1 shows the descriptive statistics and correlations between the study variables. The results indicated in the above table show that the job crafting was positively and significantly correlated with job satisfaction $(r=0.727$, $\mathrm{p}<0.001)$ and with employee engagement $(\mathrm{r}=0.792, \mathrm{p}<0.001)$, however, significantly and negatively correlated with turnover intention $(\mathrm{r}=-0.586, \mathrm{p}<0.001)$.

Table 1: Descriptive Statistics and Correlation Analysis

\begin{tabular}{lllllll}
\hline & & Mean & S. Dev. & 1 & 2 & 3 \\
\hline 1 & CRAFT & 3.391 & 0.8849 & & & \\
2 & SATISF & 3.6053 & 1.09043 & $.727^{* *}$ & & $.748^{* *}$ \\
3 & ENGAG & 3.8158 & 1.01536 & $.792^{* *}$ & $-.644^{* *}$ & $-.656^{* *}$ \\
4 & TURN & 2.2606 & 1.39456 & $-.586^{* *}$ & $-.60 .748,0001)$ \\
\hline
\end{tabular}

Job satisfaction is positively and significantly correlated with employee engagement $(\mathrm{r}=0.748, \mathrm{p}<0.001)$ and negatively and significantly correlated with turnover intention $(\mathrm{r}=-0.644, \mathrm{p}<0.001)$. Employee engagement has been found significantly and negatively correlated with turnover intention $(r=-0.656, p<$ $0.001)$.

\subsection{Hypotheses Testing}

The relationships hypothesized in the study model were tested through linear regression analysis. Table 2 (a, b, c, and d) presents the outcomes of hypotheses testing.

Table 2a: The Effect of Job Crafting on Job Satisfaction

\begin{tabular}{lllll}
\hline Dependent Variable: Job Satisfaction & & & & \\
\hline Independent Variables & $\mathrm{B}$ & Beta & $\mathrm{t}$ value & $\mathrm{p}$ value \\
\hline (Constant) & 0.569 & & 2.63 & $<.001$ \\
Job Crafting & 0.895 & 0.727 & 14.501 & $<.001$ \\
\hline
\end{tabular}

$\mathrm{R}=.727 \mathrm{R} 2=.528 \mathrm{~F}=210.283 \mathrm{P}=<.001$

$\mathrm{p}<0.001$

Table 2a shows that job crafting positively influenced job satisfaction with beta $0.727, \mathrm{p}<0.001$, which supports $\mathrm{H} 1$ of the study.

Table 2b: The Effect of Job Crafting on Employee Engagement

\begin{tabular}{lllll}
\hline Dependent Variable: Employee Engagement & & & & \\
\hline Independent Variables & $\mathrm{B}$ & Beta & $\mathrm{t}$ value & $\mathrm{p}$ value \\
\hline (Constant) & 0.734 & & 4.101 & $<.001$ \\
Job Crafting & 0.909 & 0.792 & 17.79 & $<.001$ \\
\hline
\end{tabular}

$\mathrm{R}=.792 \mathrm{R} 2=.627 \mathrm{~F}=316.237 \mathrm{P}=<.001$

$\mathrm{p}<0.001$

Table $2 \mathrm{~b}$ shows that the respondent's job crafting has positively affected their work engagement with beta $0.792, \mathrm{p}<0.001$, at $95 \%$ confidence level, supporting $\mathrm{H} 2$.

Table 2c: The Effect of Job Satisfaction on Employee Engagement

Dependent Variable: Employee Engagement

\begin{tabular}{lllll}
\hline Independent Variables & $\mathrm{B}$ & $\mathrm{Beta}$ & $\mathrm{t}$ value & $\mathrm{p}$ value \\
\hline (Constant) & 1.304 & & 7.686 & $<.001$ \\
Job Satisfaction & 0.697 & 0.748 & 15.46 & $<.001$ \\
\hline
\end{tabular}

$\mathrm{R}=.748 \mathrm{R} 2=.560 \mathrm{~F}=239.008 \mathrm{P}=<.001$

$\mathrm{p}<0.001$

The investigation of the impact of job satisfaction on employee engagement has revealed that the respondents' job satisfaction have positively influenced their engagement at work with beta $0.748, \mathrm{p}<0.001$ at $95 \%$ confidence level. 
Table 2d: The Effect of Job Satisfaction and Employee Engagement on Turnover Intention

Dependent Variable: Turnover Intention

\begin{tabular}{lllll}
\hline Independent Variables & $\mathrm{B}$ & Beta & $\mathrm{t}$ value & $\mathrm{p}$ value \\
\hline (Constant) & 5.939 & & 20.467 & $<.001$ \\
Job Satisfaction & -0.444 & -0.347 & -4.381 & $<.001$ \\
Employee Engagement & -0.545 & -0.397 & -5.006 & $<.001$ \\
\hline
\end{tabular}

$\mathrm{R}=.695 \quad \mathrm{R} 2=.484 \mathrm{~F}=87.528 \mathrm{P}=<.001$

$\mathrm{p}<0.001$

Table $2 \mathrm{~d}$ has revealed that the respondents' satisfaction and engagement have collectively negatively influenced the turnover intention with beta $0.695, \mathrm{p}<0.001$, at $95 \%$ confidence level. Hence supporting $\mathrm{H} 4$ and H5.

4.3 Goodness of Fit Model using Path Analysis Technique:

In Table 3a, the results revealed that the empirical data regenerated the measurement model and indicators of overall alignment with the scale of model of study. Satisfactory fit to the data has been experienced as per chi square, degrees of freedom ratio, comparative fit, incremental fit, and root mean square error. Based on the supportive fit indices, the model fits the data as chi-square value $=0.425(\mathrm{p}<0.05), \mathrm{RMSA}=0.000(\mathrm{p}<0.08)$, $\mathrm{NFI}=0.999(\mathrm{p} \geq 0.95), \mathrm{CFI}=1(\mathrm{p} \geq 0.90), \mathrm{GFI}=0.999(\mathrm{p} \geq 0.95)$, AGFI=0.989 $(\geq 0.90)$, TLI=1.007 $(\mathrm{p} \geq 0.95)$.

Table 3a: Model Fit Results

\begin{tabular}{|l|l|}
\hline Statistics & Model fit result \\
\hline X2/df & 0.425 \\
\hline RMSA & 0.000 \\
\hline NFI & 0.999 \\
\hline CFI & 1 \\
\hline GFI & 0.999 \\
\hline AGFI & 0.989 \\
\hline TLI & 1.007 \\
\hline
\end{tabular}

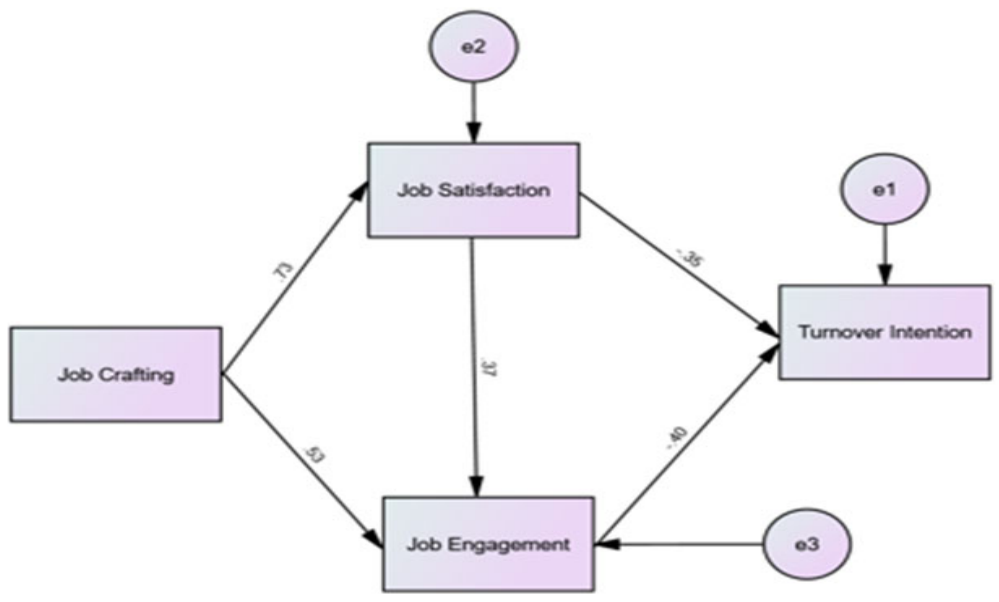

Figure 2. Path analysis

In Table $3 b$, path analysis results revealed similar outcomes as linear regression analysis. Job satisfaction and employee engagement have a moderating role between job crafting and turnover intention. Moreover, the results found that the job crafting was positively effect on job satisfaction (.895) and with employee engagement (.604). Besides that, a positive effect with employee engagement on job satisfaction (.341). However, the results indicated a negative effect on turnover intention with job satisfaction (-.444) and with employee engagement ($.545)$. 
Table 3b: Bath Analysis

\begin{tabular}{|lll|lcll|}
\hline & & & Estimate & S.E. & C.R. & P \\
\hline SATISF & $<---$ & CRAFT & .895 & .062 & 14.540 & $* * *$ \\
ENGAG & $<---$ & CRAFT & .604 & .068 & 8.935 & $* * *$ \\
ENGAG & $<---$ & SATISF & .341 & .055 & 6.209 & $* * *$ \\
TURN & $<---$ & SATISF & -.444 & .101 & -4.404 & $* * *$ \\
TURN & $<---$ & ENGAG & -.545 & .108 & -5.033 & $* * *$ \\
\hline
\end{tabular}

The findings have authenticated the presence of negative influence of job satisfaction and work engagement as mediators in the relationship between job crafting and turnover intentions. Job crafting has been found significantly suppressing the turnover intentions among the employees. Furthermore, employees' work engagement and their job satisfaction have moderated the job crafting-turnover intention relationship.

\section{Discussion}

The study was conducted to extend the insights on the subject relationship and make a notable contribution to the literature by examining the relationship between job crafting and turnover intentions and the effect of job satisfaction and work engagement as mediators on this relationship in the context of the tight culture of Saudi Arabia. The findings are in line with the relevant past studies, comprehensively reviewed for composing the hypothesis.

When the employees are allowed to actively change the way they do their jobs, they are more likely to be engaged in their work for bringing positive performance on the board. The job crafting-work engagement relationship was hypothesized as positive in the study. Supporting the hypothesis, the findings have been validated by the past studies focusing on the positive correlation of this relationship (Tims, Bakker, Derks, and Rhenen, 2013; Siddiqi, 2015; Beer, Tims, \& Bakker, 2016; Aldrin\&Merdiaty, 2019). Siddiqi (2015) found that the job crafting behavior of private service sector employees increases their work engagement.

Job crafting enables employees to turn the undesirable situation into the aspired ones by redesigning their job in the way they consider it would improve performance and productivity. Having the freedom to change different aspects of the job, the employees can better utilize their strengths and capitalize on their weaknesses, which, in turn, increases their job satisfaction. The finding of the positive relationship between job crafting and job satisfaction is in line with several past studies (Ghitulescu, 2006; Slemp\&Vella-Brodrick, 2014; Cheng, J.-C., \& O-Yang, 2018; Ren, Cao, \& Chin, 2020).

Whenever it comes to increase employees' productivity, workplace efficiency, resource utilization, customer retention rate, and financial well-being of the organization, one of the frequently considered meaningful strategies tends to be workplace engagement. Job satisfaction is the gateway to work engagement. An intrinsically satisfied employee tends to be more engaged at the workplace than a dissatisfied one. The higher the satisfaction, the more an employee tends to be dedicated at work. The findings of our study support the rationalized arguments of the past studies regarding the subject relationship (Kasparkova, Vaculík, Prochazka, \&Schaufeli, 2018; Park \& Johnson, 2019; Zhang, Bian, Bai, Kong, Liu, Chen, \& Li, 2020).

Within an organization, job satisfaction secures the role of a predecessor of desirable outcomes such as commitment to the organization's success, improved performance, and willingness to accept tasks beyond job descriptions. At the same time, it suppresses negative emotions and behaviors such as absenteeism, job stress, and, above of all, turnover intentions. The study has found that there is a negative relationship between job satisfaction and turnover intentions. These findings are in line with several past studies (Randhawa, 2007; Amah, 2009; Alam and Asim, 2019; Liu, Zhu, Wu, and Mao, 2019; Rahman, 2020). Randhawa (2007) has found that the more the employees are satisfied, the lower they tend to have turnover intention. High job satisfaction triggers high performance, notable contributions to the achievement of goals, and organization-wide recognition of the employee, which, in turn, eliminates the chances of turnover intentions. A satisfied employee tends to stay with a company as long as the factors, stimulating satisfaction, are actively present. An internally satisfied employee does not have the intention to leave the company even in the case of a reduction in compensation and benefits. However, if the triggers are external, an employee will have the intention to leave the company as soon as the triggers are no longer available. According to Alam and Asim (2019), the employers need to carefully design the strategies to build and enhance employees' job satisfaction for reducing employees' voluntary turnover.

The engaged employees have the sense of being valued at the workplace, which subsides their intentions to leave the job because such a sense of freedom may not be realized in a new workplace. The study has found an inverse relationship between work engagement and turnover intention, which has been supported by past studies (Schaufeli, 2002; Kim, 2017; Park \& Johnson, 2019). 


\subsection{Limitations of the Research}

Even though this study is the first to investigate the profound relationship between job crafting and employees' turnover intention while assessing the impact of job satisfaction and work engagement, as mediators, on the subject relationship in a country with a low tolerance for uncertainty and high collectivism, however, it has some limitations. The study has not investigated the subject relationships among the public sector employees, where it is important to investigate the impact of job crafting on turnover intentions due to embedded rigid policies, strict rules, bureaucratic structure, clearly defined reporting lines, and difficult-to-modify job descriptions. Another limitation of the study is that it has not investigated the difference of the subject relationship based on gender. It could investigate whether job crafting suppresses turnover intentions more among males than females. Similarly, the study could investigate the intensity of the relationship in relation to other demographic characteristics such as age and income, etc. by considering their role as mediators. Another limitation of the study is that it has not considered the role of leadership in job crafting-turnover intention, job crafting-job satisfaction, and job satisfaction-work engagement relationships. Another limitation is related to the generalizability of the findings. The data was collected from Saudi employees, therefore, the findings can't be generalized to the employees working in countries having low-context cultures.

\subsection{Recommendations and Future Research}

Although extensive research has been done, however, job crafting phenomenon is yet to be explored more thoroughly. For future research, it is suggested that the scholars should assess the short-term and long-term impact of job crafting on the company because variations in the way jobs are designed and performed might produce either positive or negative results for the company. Moreover, the role of a manager in an employee's job crafting should be assessed. The subject relationship of the study can be more dynamically assessed by investigating the mediating impact of managerial support to employees while redesigning their job demands and determining the resources.

\subsection{Managerial Implications}

The study has offered several valuable implications for the business entities. Job crafting helps managers in inducing employees' positive behavior at work and towards their jobs. When an employee is given the opportunity to craft his/her job, he tends to be more engaged at the workplace and more committed to the organization's success. However, the managers, in the high-context cultures, should be the helping hands of their employees while they craft their jobs due to low tolerance of uncertainty. The job crafting, itself wouldn't deliver the expected results, unless the performance and employees' attitude towards jobs are monitored. In today's aggressively competitive environment, the managers shouldn't ignore employees' concerns and issues at work because they can negatively impact their job satisfaction and work engagement, which, in turn, reduce the positive impact of job crafting on turnover intentions.

\section{Conclusion}

Considering the importance of employees' autonomy to design their jobs at work and the managerial and scholarly attention this phenomenon has attained, this study was conducted to investigate the impact of employees' roles in designing different aspects of their jobs and determining the resources to perform duties on their turnover intentions considering the impact of employees' job satisfaction and employee engagement as mediators, in the Saudi context. As the subject relationships were hypothesized based on the comprehensive review of relevant past studies, the investigatory assessment has validated that job crafting subsides the turnover intentions among employees. It has also been confirmed that job crafting makes employees more satisfied at their jobs, which provokes their engagement at work and, in turn, abates turnover intentions among employees.

The study has contributed to the literature by investigating the impact of job crafting on employees' turnover intentions, while assessing the role of job satisfaction and work engagement as mediators, in a collectivistic society for the first time. The management in Saudi companies should create the employee-friendly environment promoting job crafting opportunities for employees which will, in turn, reduce the existing or projected turnover intentions among them. Each employee should be taken as an individual with varying needs and wants than others, thereby develop strategic incentives for each of the employees to drive their internal and external motivation which will raise their satisfaction level and increase their engagement at work and discourage them from having turnover intentions.

\section{References}

Alam, A., \& Asim, M. (2019). Relationship between job satisfaction and turnover intention. International Journal of Human Resources Studies, 2162-3058.

Aldrin, N., \& Merdiaty, N. (2019). Effect of job crafting on work engagement with mindfulness as a mediator. Cogent Psychology , 6 (1), 1684421 . 
Al-Ruwaitea, A. S. (2004). Individualism and collectivism in Saudi Arabia. Centre of Research, Department of Psychology, King Saud University, Riyadh, Saudi Arabia.

Amah, O. E. (2009). Job Satisfaction and Turnover Intention Relationship: The Moderating Effect of Job Role Centrality and Life Satisfaction. Research \& Practice in Human Resource Management, 17(1).

Arnoux-Nicolas, C., Sovet, L., Lhotellier, L., Fabio, A. D., \& Bernaud, J.-L. (2016). Perceived work conditions and turnover intentions: The mediating role of meaning of work. Frontiers in Psychology, 7, 704.

Azeez, R. O., Jayeoba, F., \& Adeoye, A. O. (2016). Job satisfaction, turnover intention and organizational commitment. Journal of Management Research , 8 (2), 102-114 .

Bakker, A. B., Tims, M., \& Derks, D. (2012). Proactive personality and job performance: The role of job crafting and work engagement. Human Relations , 65, 1359-1378.

Barbosa de Oliveira, L. \& da Costa Rocha, J. (2017). Work engagement: individual and situational antecedents and its relationship with turnover intention. Review of Business Management, 19(65), p. 415-431. doi: 10.7819/rbgn.v19i64.3373

Beer, L. T., Tims, M., \& Bakker, A. B. (2016). Job crafting and its impact on work engagement and job satisfaction in mining and manufacturing. South African Journal of Economic and Management Sciences, $19(3), 44-412$.

Bindl, U. K., Unsworth, K. L., Gibson, C. B., \& Stride, C. B. (2019). Job crafting revisited: Implications of an extended framework for active changes at work. Journal of Applied Psychology, 104(5), 605.

Caillier, J. G. (2020). The impact of workplace aggression on employee satisfaction with job stress, meaningfulness of work, and turnover intentions. Public Personnel Management.

Chang, W. J. A., Wang, Y. S., \& Huang, T. C. (2013). Work design-related antecedents of turnover intention: A multilevel approach. Human Resource Management, 52(1), 1-26

Chen, C.-Y., Yen, C.-H., \& Tsai, F. C. (2014). Job crafting and job engagement: The mediating role of person-job fit. International Journal of Hospitality Management , 37, 21-28.

Chen, J.-C., \& Yi., O. (2018). Hotel employee job crafting, burnout, and satisfaction: The moderating role of perceived organizational support. International Journal of Hospitality Management , 72, 78-85.

Chiu, C. M. (2017). IT Professionals' Turnover Intention: The Role of Job Crafting and Engagement. In PACIS (p. 259)

Chiu, C. Y., \& Hong, Y. Y. (2013). Social psychology of culture. Psychology Press

Clausen, T., \& Borg, V. (2011). Job demands, job resources and meaning at work. Journal of Managerial Psychology .

Dominguez, L. C., Stassen, L., Grave, W. d., Sanabria, A., Alfonso, E., \& Dolmans, D. (2018). Taking control: Is job crafting related to the intention to leave surgical training? PloS one , 13 (6), e0197276.

Dubbelt, L., Demerouti, E., \& Rispens, S. (2019). The value of job crafting for work engagement, task performance, and career satisfaction: longitudinal and quasiexperimental evidence. European Journal of Work and Organizational Psychology , 28 (3), 300-314.

Esteves, T., \& Lopes, M. P. (2017). Crafting a calling: The mediating role of calling between challenging job demands and turnover intention. Journal of Career Development , 44, 34-48.

Freund, A. (2005). Commitment and job satisfaction as predictors of turnover intentions among welfare workers. Administration in social work , 29 (2), 521.

Ghitulescu, B. E. (2006). Shaping tasks and relationships at work: Examining the antecedents and consequences of employee job crafting (Doctoral dissertation). University of Pittsburgh. Pittsburgh, United States.

Heuvel, M. V., Demerouti, E., \& Peeters, M. C. (2015). The job crafting intervention: Effects on job resources, self - efficacy, and affective well - being. Journal of Occupational and Organizational Psychology , 88 (3), 511-532.

Huang, T.-C., Lawler, J., \& Lei, C.-Y. (2007). The effects of quality of work life on commitment and turnover intention. Social Behavior and Personality: an international journal , 35 (6), 735-750.

Iddagoda, A., Opatha, H. H. P., \& Gunawardana, K. D. (2016). Towards a conceptualization and an operationalization of the construct of employee engagement. International Business Research, 9(2), 85-98. doi:10.5539/ibr.v9n2p85

Ingusci, E., Callea, A., Chirumbolo, A., \& Urbini, F. (2016). Job crafting and job satisfaction in a sample of Italian teachers: the mediating role of Perceived Organizational Support. Electronic Journal of Applied Statistical Analysis , 9 (4), 675-687.

Jang, Y., Lee, A. A., Zadrozny, M., Bae, S.-H., Kim, M. T., \& Marti, N. C. (2017). Determinants of job satisfaction and turnover intent in home health workers: The role of job demands and resources. Journal of Applied Gerontology , 56, 56-70.

Janik, M. (2015). Meaningful work and secondary school teachers' intention to leave. South African Journal of Education , 35 (2), 1008.

Jourdain, G., \& Chenevert, D. (2010). Job demands-resources, burnout and intention to leave the nursing 
profession: A questionnaire survey. International journal of nursing studies , 47 (6), 709-722.

Karatepe, O. M., \& Eslamlou, A. (2017). Outcomes of job crafting among flight attendants. Journal of Air Transport Management , 62, 34-43.

Kasparkova, L., Vaculík, M., Procházka, J., \& Schaufeli, W. B. (2018). Why resilient workers perform better: The roles of job satisfaction and work engagement. Journal of Workplace Behavioral Health, 33(1), 43-62.

Kim, W. (2017). Examining mediation effects of work engagement among job resources, job performance, and turnover intention. Performance Improvement Quarterly, 29(4), 407425. doi:10.1002/piq.21235

Klehe, U.-C., Zikic, J., Vianen, A. E., \& Pater, I. E. (2011). Career adaptability, turnover and loyalty during organizational downsizing. Journal of Vocational Behavior, 79 (1), 217-229.

Lambert, E. G., Hogan, N. L., \& Barton, S. M. (2001). The impact of job satisfaction on turnover intent: a test of a structural measurement model using a national sample of workers. The Social Science Journal , 38 (2), $233-250$

Liu, J., Zhu, B., Wu, J., \& Mao, Y. (2019). Job satisfaction, work stress, and turnover intentions among rural health workers: a cross-sectional study in 11 Western provinces of China. BMC family practice, 20(1), 1-11.

Mowday, R. T., Koberg, C. S., \& McArthur, A. W. (1984). The psychology of the withdrawal process: A crossvalidation test of Mobley's intermediate linkages model of turnover in two samples. Academy of Management Journal, 27(1), 79-94.

Opre, B., Paduraru, L., \& Iliescu, D. (2020). Job Crafting and Intent to Leave: The Mediating Role of Meaningful Work and Engagement. Journal of Career Development .

Oprea, B. T., Barzin, L., Vîrga, D., Iliescu, D., \& Rusu, A. (2019). Effectiveness of job crafting interventions: A meta-analysis and utility analysis. European Journal of Work and Organizational Psychology , 28 (6), 723 741.

Oyserman, D., \& Lee, S. W. (2008). Does culture influence what and how we think? Effects of priming individualism and collectivism. Psychological bulletin, 134(2), 311.

Park, K. A., \& Johnson, K. R. (2019). Job Satisfaction, Work Engagement, and Turnover Intention of CTE Health Science Teachers. International journal for research in vocational education and training, 6(3), 2224242.

Parvin, M. M., \& Kabir, M. M. N. (2011). Factors affecting employee job satisfaction of pharmaceutical sector. Australian Journal of Business and Management Research, 1, 113-123.

Podsakoff, N. P., LePine, J. A., \& LePine, M. A. (2007). Differential challenge stressor-hindrance stressor relationships with job attitudes, turnover intentions, turnover, and withdrawal behavior: a meta-analysis. Journal of applied psychology , 92, 438-454.

Rahman, S. M. (2020). Relationship between Job Satisfaction and Turnover Intention: Evidence from Bangladesh. Asian Business Review, 10(2), 99-108.

Randhawa, G. (2007). Relationship between job satisfaction and turnover intentions: An empirical analysis. Indian Management Studies Journal, 11(2), 149-159.

Ren, T., Cao, L., \& Chin, T. (2020). Crafting jobs for occupational satisfaction and innovation among manufacturing workers facing the COVID-19 crisis. International Journal of Environmental Research and Public Health, 17(11), 3953.

Schaufeli, W. B., Bakker, A. B., \& Salanova, M. (2006). The measurement of work engagement with a short questionnaire: A cross-national study. Educational and psychological measurement , 66 (4), 701-716.

Schaufeli, W. B., Bakker, A. B., \& Salanova, M. (2006). The measurement of work engagement with a short questionnaire: A cross-national study. Educational and Psychological Measurement, 66(4), 701-716. doi: $10.1177 / 0013164405282471$.

Schaufeli, W. B., Salanova, M. S., González-Romá, V. A., \& Bakker, A. B. (2002). The measurement of engagement and burnout: A two sample confirmatory factor analytic approach. Journal of Happiness Studies, 3(1), 71-92.

Siddiqi, M. A. (2015). Work engagement and job crafting of service employees influencing customer outcomes. Vikalpa: The Journal of Decision Makers, 40(3), 277-292.

Sjoberg, A., \& Sverke, M. (2000). The interactive effect of job involvement and organizational commitment on job turnover revisited: A note on the mediating role of turnover intention. Scandinavian Journal of Psychology , 41 (3), 247252.

Slåtten, T., Svensson, G., \& Sværi, S. (2011). Service quality and turnover intentions as perceived by employees: Antecedents and consequences. Personnel Review .

Slemp, G. R., \& Vella-Brodrick, D. A. (2014). Optimising employee mental health: The relationship between intrinsic need satisfaction, job crafting, and employee wellbeing. Journal of Happiness Studies, 15(4), 957977.

Tett, R. P., \& Meyer, J. P. (1993). Job satisfaction, organizational commitment, turnover intention, and turnover: path analyses based on meta - analytic findings. Personnel Psychology , 46 (2), 259-293. 
Tim, M., Bakker, A. B., \& Derks, D. (2013). The impact of job crafting on job demands, job resources, and wellbeing. Journal of occupational health psychology , 18 (2), 230.

Tims, M., \& Bakker, A. B. (2010). Job crafting: Towards a new model of individual job redesign. SA Journal of Industrial Psychology, 36 (2), 1-9.

Tims, M., Bakker, A. B., \& Derks, D. (2012). Development and validation of the job crafting scale. Journal of vocational behavior, 80 (1), 173-186.

Tims, M., Bakker, A. B., Derks, D., \& Rhenen, W. V. (2013). Job crafting at the team and individual level: Implications for work engagement and performance. Group \& Organization Management, 38(4), 427-454.

Van den Heuvel, M., Demerouti, E., \& Peeters, M. C. W. (2015). The job crafting intervention: Effects on job resources, self-efficacy, and affective well-being. Journal of Occupational and Organizational Psychology, $88,1-22$

Vermooten, N., Boonzaier, B., \& Kidd, M. (2019). Job crafting, proactive personality and meaningful work: Implications for employee engagement and turnover intention. SA Journal of Industrial Psychology , 45 (1), $1-13$.

Wrzesniewski, A., \& Dutton, J. E. (2001). Crafting a job: Revisioning employees as active crafters of their work. Academy of management review , 26 (2), 179201.

Yang, Jixia, Mossholder, Kevin W., \& Peng, T. K. (2009). Supervisory procedural justice effects: The mediating roles of cognitive and effective trust. The Leadership Quarterly, 20(2), 143-154.

Zhang, T., \& Li, B. (2020). Job crafting and turnover intention: The mediating role of work engagement and job satisfaction. Social Behavior and Personality: An International Journal , 48 (2), e8759.

Zhang, X., Bian, L., Bai, X., Kong, D., Liu, L., Chen, Q., \& Li, N. (2020). The influence of job satisfaction, resilience and work engagement on turnover intention among village doctors in China: a cross-sectional study. BMC health services research, 20, 1-11. 